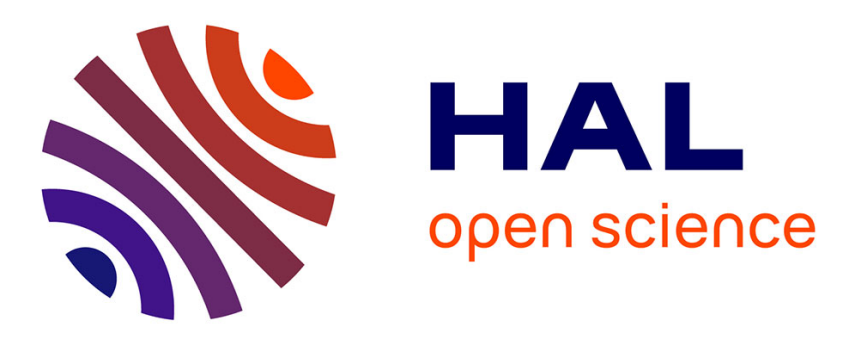

\title{
Identifying Key Aspects of Success for Product Service Systems
}

Nathaniel Smith, Thorsten Wuest

\section{To cite this version:}

Nathaniel Smith, Thorsten Wuest. Identifying Key Aspects of Success for Product Service Systems. IFIP International Conference on Advances in Production Management Systems (APMS), Sep 2017, Hamburg, Germany. pp.231-238, 10.1007/978-3-319-66923-6_27 . hal-01666194

\section{HAL Id: hal-01666194 https://hal.inria.fr/hal-01666194}

Submitted on 18 Dec 2017

HAL is a multi-disciplinary open access archive for the deposit and dissemination of scientific research documents, whether they are published or not. The documents may come from teaching and research institutions in France or abroad, or from public or private research centers.
L'archive ouverte pluridisciplinaire HAL, est destinée au dépôt et à la diffusion de documents scientifiques de niveau recherche, publiés ou non, émanant des établissements d'enseignement et de recherche français ou étrangers, des laboratoires publics ou privés.

\section{(c)(1)}

Distributed under a Creative Commons Attribution| 4.0 International License 


\title{
Identifying Key Aspects of Success for Product Service Systems
}

\author{
Nathaniel Smith \& Thorsten Wuest \\ Industrial and Management Systems Engineering, Benjamin M. Statler College of En- \\ gineering and Mineral Resources, West Virginia University, Morgantown, WV, USA \\ nlsmith@mix.wvu.edu \& thwuest@mail.wvu.edu
}

\begin{abstract}
As companies struggle with the various challenges of their PSS, identification and elimination of possible errors and potential challenges early in the design phase is crucial. This paper aims to identify the universal key aspects of success for a PSS; thus, providing a general foundation for many companies within the industry to focus their initial efforts. Utilizing historical and contemporary literature within the PSS field, one central aspect was identified with three additional aspects serving to support the core aspect that all PSS are centered around - creating customer value. Standardization, product usage information (PUI), and environmental sustainability all support the goal of ultimately adding customer value. While there is a potentially unlimited number of additional individual supporting aspects that are important and contribute to this objective, these do not apply to all PSS universally. As a combinational effort, the three supporting aspects help to ensure that value is added to the customer in different, but related routes. These aspects involved may be utilized to allow companies to examine and analyze their current PSS and implement these aspects into their PSS operations and/or, ideally, reflecting on them during the PSS design phase. A limitation of this study is, that the universal nature of the 4 identified key aspects reflects only the PSS cases within the literature reviewed.
\end{abstract}

Keywords: Product Service Systems; Servitization; PSS; IPSS; Smart Services

\section{$1 \quad$ Introduction}

Companies historically focus primarily on their manufacturing processes and optimizing the design of their products. A large portion of their revenue is often still generated from the initial sale. However, a growing part of their total lifecycle revenue can be generated during the after-sale phase (Middle of Life - MOL) (Mahut, Daaboul, Bricogne, \& Eynard, 2016). Entering service agreements and contracts can allow a company, e.g., to perform preventative maintenance, scheduled diagnostics, and other advanced services for the users of their products (customers). These service agreements can block out other competitors, reduce costs for the manufacturer and customer, and add value to the customer.

A Product Service System (PSS) is a relatively new strategy where companies focus on both products and services with the goal of adding value to the customer/user. For 
example, a jet engine manufacturer will sell thrust, not the engines themselves any longer. A printing company will sell printed pages, not physical printers. This mindset is quite different from the traditional manufacturing avenue. Companies such as these, focus on the result, the value, and experience provided to the customer. Benefits from these PSS are found to include: reduced costs, reduced environmental footprint, lower overhead costs, more technology-driven systems, and ultimately more revenue.

Problem Scope: While many PSS are generally considered successful, they are not immune to various challenges and difficulties. Companies face these challenges on a daily basis and are confronted with mishaps in their current PSS. Some aspects of a PSS may be strong, but at the same time other areas may prove problematic. It is suggested to identify, understand, reduce and eliminate the possibility of errors and potential challenges early in the design phase while increasing the capabilities and flexibility of a PSS.

Main Objective: The main objective of the paper is to identify the key success aspects that are universal to all PSS. The main question to be answered is whether there is a set of common aspects that successful PSS have in common and whether they can be identified and potentially utilized to improve current product service systems or assist in developing an upcoming PSS. Furthermore, utilizing resources from outside one's industry or obtaining new successful concepts may help to build a stronger and more resilient process. Analyzing these lessons learned and companies' successful PSS as well as their operations, allow for a business to learn and strengthen their own (current or future) PSS if adapted and implemented carefully.

Methodology: In the following section, four aspects of PSS operations have been identified that characterize successful PSS through a comprehensive review of current literature. The literary review covered mostly journal articles that were published within the last five years while others were within the last ten years. This selection process served as a method of obtaining contemporary information regarding today's industries. A few articles provided a historical foundation of PSS principles that were beneficial to the support of this paper's claims (Blumberg, 1994). Utilizing these historical principals allowed for a basis to help build upon other claims through more recent literature. Various databases were searched through to determine the paper selection. The Services Industries Journal and Journal of Cleaner Production were two of the major journals used for the literary review. Both journals have provided historical articles as well as recent literature that entails current technology-driven applications.

Selection of the articles was completed through evaluating studies of successful PSS. Based on the various articles' studies of current PSS, many articles identified how those PSS operated, interactions they had with their customer, and what the company valued overall. First, a set of literature was reviewed to help form this model of successful key aspects. Pulling from historical and recent literature, case studies were examined for the core values that ensured success of the PSS. Next, supporting literature was reviewed and integrated to validate the model through a deeper evaluation. This resulted in most of the PSS key success aspects to become apparent.

Extracting each of these successful aspects into a summary and compiling the similar aspects together allowed for the main aspects to emerge. Completing this literary re- 
view revealed two interesting discoveries. First, each of the successful PSS reviewed consisted of these four main aspects that ensured the advancement and success of the individual PSS. Second, these four main aspects were also highly related and integrated together. Implementing one aspect would ease the ability to implement another aspect. Furthermore, impacting just one aspect would have a considerable effect on other aspects. Derivation into the details of the aspects were completed to see how closely dependent they are.

\section{Identifying Key Aspects}

The first aspect, "Center Around Customer Value" is the overarching goal and 'raison d'être' of what encompasses a PSS by definition (Blumberg, 1994; Boehm \& Thomas, 2013). Li also discusses the framework of value co-creation in PSS through digital technology and connectivity in his paper (Li \& Found, 2017). With value co-creation (customer value) at the center of the framework, other stakeholders stem off from this main aspect.

In this paper, three additional aspects serve to support the overall goal of adding customer value; which were identified as being universally applicable across all successful PSS studied in this research. These include, standardization, product usage information (PUI), and environmental sustainability. As each of these aspects are individually sound on their own, customer value is supported by these additional aspects. This development is supported by Li's value co-creation framework where stakeholders serve to provide each of the key aspects identified (Li \& Found, 2017).

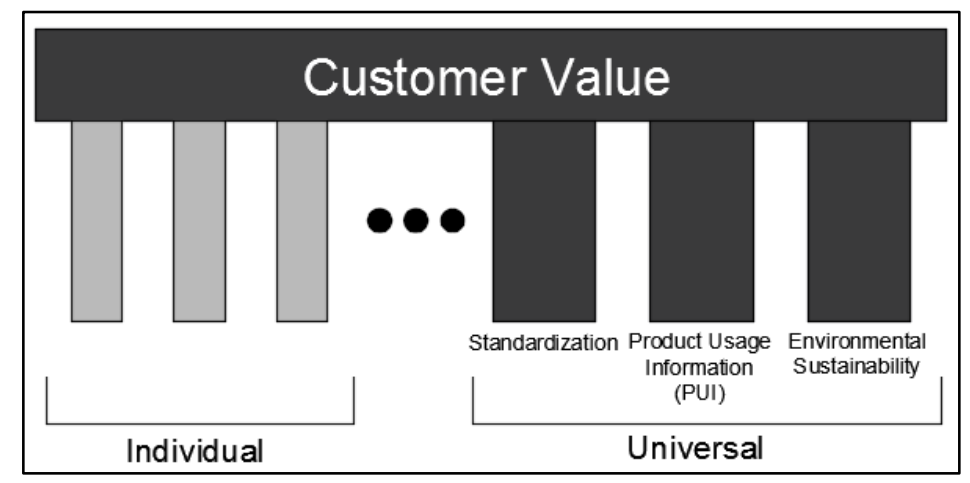

Fig. 1. PSS key supporting aspects to customer value

Understanding how each of the key aspects are connected ensures for a more transparent and strategic implementation. This is illustrated in Fig. 1 with the four key aspects highlighted in a darker shade. From the research, these three aspects are universal to nearly all PSS reviewed in the literature. Regarding Fig. 1, the left tiers are given to show that there are other key aspects in other varieties of PSS, but this was not the scope of the paper. The three main tiers are universal to nearly all PSS. Each of the universal aspects has interaction and dependency with one another. However, the 
scope of the paper was to identify these aspects and their combinational effort to support customer value for a PSS.

\subsection{Center Around Customer Value}

The PSS operations should be centered around customer value (Colen \& Lambrecht, 2013; Mont, 2002). A trusting relationship between the customer and manufacturer is formed through the continued use of a PSS and the value it delivers. Continued interaction and effective communication will strengthen business relationships and ensure that the customer is obtaining added value. Due to increased servicing, higher quality parts and services are implanted to ensure that the product is operating correctly and efficiently. A company's product is able to last longer and ensure for a longer life cycle. This generally benefits both the customer and the company providing the PSS. For the customer, a PSS can provide value through higher quality products and broad customization (Baines et al., 2007).

Overall, monitoring, maintenance, and administrative tasks are completely hands-off to the customer as it is transferred to the manufacturer. For the manufacturer, a PSS allows for a great competitive edge and market opportunities. Companies can serve their customers with more value through increasing service elements (T. S. Baines et al., 2007). To maintain customer loyalty, manufacturers and customers enter into a service agreement. These agreements allow for manufacturers to serve the customer by using their innovative and proprietary processes and products for their customers creating customer value. This also helps hinder competitors from offering similar systems to customers. Enhancing the manufacturer's overall PSS will correlate to a stronger bond between the company and their customers (Wuest \& Wellsandt, 2016). In turn, utilizing a PSS to provide extensive services could potentially be a threat to the manufacturing efforts. One department pushes for manufacturing more units while the PSS efforts support less manufacturing through increased service - a contradiction. A company must surpass these functional barriers by working together as one synchronized unit (Colen \& Lambrecht, 2013). Adopting a product-service culture, implementing internal processes and capabilities presents its own challenges (Wuest \& Wellsandt, 2016). A company should be able to stimulate both manufacturing and PSS efforts simultaneously. As a core promise of PSS, it is no wonder that an emphasis on the customer value is a key aspect that successful PSS have in common. In addition, the following key aspects support this customer value endeavor.

\subsection{Standardization}

Overall, a successful PSS must limit uncertainty and complexity (Colen \& Lambrecht, 2013). This statement means that standardization of purchasing options and additional services is crucial to the success of the company. However, a balance must be reached between standardization and customization (Colen \& Lambrecht, 2013), especially with PSS. Marketing too many options can confuse a customer as well as increase costs (Blumberg, 1994). Modules, packages, and bundles should be utilized to help combat this issue. Standard service elements can be combined into a menu for a cus- 
tomer to choose. Furthermore, customers perceive these solidified options as higher service and value by receiving maximum value for each package (Blumberg, 1994). If a customer desires a few extra features that is in another package, the manufacturer may be able to upsell the customer to purchase the more expensive package. In selling to a customer, only a certain amount of customer input should be accepted. Companies can agree to this only if a customer recognizes this added value and is willing to pay for the customization (Visintin, 2012). Otherwise, this only adds variability and additional costs for the company. It is best to avoid customer customization input so that the company can focus on the standardized packages that they offer (Visintin, 2012). In addition to adding customer value, this can also increase control for the manufacturer's revenue as well as reduce costs overall. There is no longer a need to have several different configurations varying in dimensions and various components. The customer feels that they are able to customize their services while the manufacturer is still keeping the options standardized. Overall, it was found that limiting uncertainty and complexity of PSS as much as possible without jeopardizing the defining value-added characteristics is a common trait of successful PSS.

\subsection{Product Usage Information (PUI)}

A PSS should fully benefit from an installed base of information on their customers/users (Blumberg, 1994). This "base" contains a variety of data about the customer, service history, usage parameters and several other data. A company may forecast demand, diagnose, and perform various analyses based on this data. Moreover, this can help schedule maintenance, diagnose problems, and serve as a great indicator for future developments. Product Usage Information (PUI) can also be key in developing future products as they assist in the development of PSS directly from customer feedback (Lutzenberger et al., 2016). Knowing how a customer uses its product, service, or PSS allows to understand the true, often implicit, requirements better. Thus, the development of targeted solutions in form of additional services or product redesign can deliver more value to the customer/user. Applying sensors and data collection devices can be a tremendous asset to both the operation and design of a PSS. The concept of analyzing this data that is collected and implementing it into future product and/or service design can be crucial to the success of the PSS. Although research on this concept is relatively new and scarce, it proves that opportunity is still available to gain a competitive edge in the marketplace. Not only will the sensor data benefit future product design, but also maintenance of the existing products. A manufacturer can gather this PUI from their various customers, which will provide the ability to schedule preventive maintenance for the components.

Regarding additional services to the main customer base and PUI, this can be enhanced through the use of a web-based PSS for maintenance, repair, and overhaul (Zhu at al., 2012). This type of web-based system allows for real-time access of customers, maintenance schedules, and an up-to-date view of product usage information. In addition to gathering data, PSS visualization using dashboards are available to display the flow and process of customer activities, state of products, and various part- 
ners (Lim et al., 2012). PUI data may be able to be implemented into this visualization to provide an overall view of the PSS process.

\subsection{Environmental Sustainability}

An indirect benefit to the company and the customer is the environmental impact. Utilizing a PSS system through cleaner production, sustainability, and more thorough eco-design, can allow for a system to have a factor of 4-20 times the environmental impact reduction than a normal production system - while maintaining the same quality of service (Roy, 2000). By switching to PSS, manufacturers can sustain the products that currently exist through upgradable components and eco-design. Furthermore, hybrid systems are also being introduced that are called "Upgradable Product Service Systems (Up-PSS)" (Pialot et al., 2017). These systems are based on upgradability, optimized maintenance, and adding customer value.

A study conducted in France, Germany, and Spain showed that many consumers dispose of $50 \%$ of vacuum cleaners, expresso machines, and other electrical household appliances even if they still work (Pialot et al., 2017). Furthermore, nearly 50\% of products accumulate three problems or more (Pialot et al., 2017). Yet, only a small portion of these consumers have considered fixing these problems instead of buying another. Rather than simply dispose of a product, consumers would rather purchase a new one. This is a call-to-action for many manufacturers worldwide.

For PSS, upgradable products and servicing can allow companies to be able to upgrade the products easily and install longer life cycle parts. Applying the product life cycle (PLC), upgrades can be easily scheduled along the timeline of the product and its related components for easy maintenance scheduling. After introducing product usage information into the PSS, a company is able to collect data on these upgradable parts. Recycling the old parts to be remanufactured is a goal that could benefit the environment tremendously. Continual developments in recyclable components that have a longer PLC is critical. Environmental impact is a continual issue that each company strives to improve upon. While not being directly connected to economic KPIs for the PSS provider, successful PSS are common in the fact that they benefit the environment in one way or another.

\section{Discussion}

Although there are several factors that might be associated with the success of a PSS, four main aspects were repeatedly identified as relevant in case studies published in recent literature. Many papers discuss different PSS operations in depth, while implementation is not as thoroughly focused (Baines et al., 2016). There is little research about how a company should implement this into one's current system - a large knowledge gap. Without this, a company may blindly upgrade their systems with faulty database integration and/or skewed data. And in the end, no data is better than "wrong" data, as the availability of wrong data leads to dangerous consequences. Re- 
search must be completed for the implementation phase of new upgrades as well as applying these concepts in the design phase.

A PSS serves to provide value to the customer and to ensure its company's products are working efficiently for their customer. Thus, customer value is the overall goal of a PSS. Supporting customer value are three additional aspects that all correlate strongly. First, standardization allows for ease of choice with predetermined packages or modules for the customer. However, customization is also balanced with these standardized modules. This adds to the customer's perceived value with providing a set of options that is still allowed to be customized, yet is kept standardized. Next, Product Usage Information (PUI) can be obtained from the customer utilizing data collection and analytics technology, e.g., IoT. This information assists in providing a basis for future product design and development, maintenance, and possible future sustainability efforts. Data collection devices can flag when certain components fail, their overall average PLC, and analyze the utilization of the company's products. In turn, the company will collect this feedback to improve their future development in their products and shift their focus to their customers' needs. Finally, environmental sustainability totalizes these efforts to ensure for a positive impact on the environment. UpPSS's products are upgradable along the PLC to ensure for recycling, reduced waste for the consumer and the manufacturer, and added-value to the customer.

\section{Conclusions and Future Outlook}

The purpose of the paper was to identify the key aspects that define successful PSS from published literature. Moving forward, companies should consider these four universal key aspects that successful PSS have in common and interpret them individually when developing an implementation plan for their own PSS business model. Though these aspects are separate, they are also dependent upon one another as shown in Fig. 1 to some extent. As a first step, companies should analyze their own business to determine how to integrate these aspects to add customer value. In turn, the other aspects will be positively impacted based on the implementation approach. More research, including the collection of a larger sample based on primary research data, is required and might lead to identifying additional aspects that commonly define successful PSS. Another area that needs to be explored is the impact that different industries and PSS business models (e.g., B2B vs. P2C) have on the identification of defining aspects. In a next step, the findings presented in this paper will be validated through primary data collection. Additional key aspects for certain industries may be identified to supplement the four universal aspects identified here.

\section{References}

Baines, T. S., Lightfoot, H. W., Evans, S., Neely, A., Greenough, R., Peppard, J., ... Michele, P. (2007). State-of-the-art in product-service systems. Proceedings of the Institution of Mechanical Engineers -- Part B -- Engineering Manufacture, 221, 1543-1552. https://doi.org/10.1243/09544054JEM858 
Baines, T., Ziaee, A., Bustinza, O. F., Guang, V., Baldwin, J., \& Ridgway, K. (2016). Servitization: Revisiting the State-of-the-art and Research Priorities. International Journal of Operations \& Production Management, (July), 1-28. https://doi.org/10.1108/IJOPM-06-2015-0312

Blumberg, D. F. (1994). Strategies for Improving Field Service Operations Productivity and Quality. The Service Industries Journal, 14(2), 262-277. https://doi.org/10.1080/02642069400000026

Boehm, M., \& Thomas, O. (2013). Looking beyond the rim of one's teacup: A multidisciplinary literature review of Product-Service Systems in Information Systems, Business Management, and Engineering \& Design. Journal of Cleaner Production, 51, 245-250. https://doi.org/10.1016/j.jclepro.2013.01.019

Colen, P. J., \& Lambrecht, M. R. (2013). Product service systems: exploring operational practices. The Service Industries Journal, 33(5), 501-515. https://doi.org/10.1080/02642069.2011.614344

Heizer, J., Render, B., \& Munson, C. (2011). Operations Management.

Lutzenberger, J., Klein, P., Hribernik, K., \& Thoben, K. D. (2016). Improving Product-Service Systems by Exploiting Information from the Usage Phase. A Case Study. Procedia CIRP, 47, 376-381. https://doi.org/10.1016/j.procir.2016.03.064

Li, A. Q., \& Found, P. (2017). Towards Sustainability: PSS, Digital Technology and Value $\begin{array}{llll}\text { Co-creation. } & \text { Procedia } & \text { CIRP, }\end{array}$ https://doi.org/10.1016/j.procir.2017.05.002

Lim, C. H., Kim, K. J., Hong, Y. S., \& Park, K. (2012). PSS Board: A structured tool for product-service system process visualization. Journal of Cleaner Production, 37, 42-53. https://doi.org/10.1016/j.jclepro.2012.06.006

Mahut, F., Daaboul, J., Bricogne, M., \& Eynard, B. (2016). Product-Service Systems for servitization of the automotive industry: a literature review. International Journal of Production Research, In Press(November), 1-19. http://dx.doi.org/10.1080/00207543.2016.1252864

Mont, O. (2002). Clarifying the concept of product - service system. Journal of Cleaner Production, 10, 237-245. https://doi.org/10.1016/S0959-6526(01)00039-7

Pialot, O., Millet, D., \& Bisiaux, J. (2017). Upgradable PSS: Clarifying a new concept of sustainable consumption/production based on upgradablility. Journal of Cleaner Production, 141, 538-550. https://doi.org/10.1016/j.jclepro.2016.08.161

Roy, R. (2000). Sustainable product-service systems. Futures, 32(3-4), 289-299. https://doi.org/10.1016/S0016-3287(99)00098-1

Visintin, F. (2012). Providing integrated solutions in the professional printing industry: The case of Océ. Computers in Industry, 63(4), 379-388. https://doi.org/10.1016/j.compind.2012.02.010

Wuest, T., \& Wellsandt, S. (2016). Design and Development of PSS - Impact on Product Lifecycle Perspective. Procedia Technology, 26(304), 152-161. https://doi.org/10.1016/j.protcy.2016.08.021

Zhu, H., Gao, J., Li, D., \& Tang, D. (2012). A Web-based product service system for aerospace maintenance, repair and overhaul services. Computers in Industry, 63(4), 338-348. https://doi.org/10.1016/j.compind.2012.02.016 